\title{
The Impact of IR 4.0 on Circular Economy and Operational Performance to Spur Financial Performance: A Game Changer Strategy
}

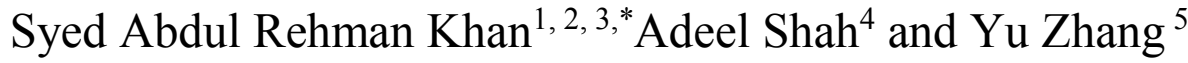 \\ ${ }^{1}$ School of Management and Engineering, Xuzhou University of Technology, Xuzhou, China \\ ${ }^{2}$ Department of Business Administration, ILMA University, Karachi, Pakistan \\ ${ }^{3}$ Beijing Key Laboratory of Urban Spatial Information Engineering, Beijing, China \\ ${ }^{4}$ Collage of Business Management (CBM) Karachi, Pakistan \\ ${ }^{5}$ School of Economics and Management, Chang'an University, Xi'an, China \\ ${ }^{*}$ Corresponding author. Email: sarehman_csco@yahoo.com
}

\begin{abstract}
The digital technologies from Industrial Revolution (I.R.) 4.0 create capabilities that positively impact organizational performances. Technology is a new frontier, and academicians, researchers, and business managers are still trying to understand its full potential. The current empirical research is an endeavor in the same direction in the context of Pakistan. The development of the hypothesis basis on the literature review to test IR 4.0, circular economy (C.E.) practices, operational performance (O.P.), and economic performance (E.P.). For hypothesis testing, the study five hundred and forty business organizations were selected as potential respondents. SEM technique is used to answer the developed hypothesis. The results reveal that IR 4.0 supports C.E. practices and O.P. while both support E.P.

Keywords: IR4.0, circular economy practices, operational performance, economic performance
\end{abstract}

\section{INTRODUCTION}

Business organizations are continuously evolving and improving their performance. The evolution in business organizations is like in any complex organic body. The system adapts according to its surroundings and performs better. Business organizations exist in an environment that has competition and impediments. New technologies are incorporated and adapted to complete organizational objectives. The technologies invented for IR4.0 are helping the organization to better connect with other members of the supply chain. The advancement in communication to share massive data from another anywhere on the globe made IR 4.0 possible. Nanomaterial and progress in computing power also improved engineering and robotics, making IR 4.0 a reality in all types of organizations, businesses, government and arm forces, education, and health services. Technologies like big data, IoT, cloud computing, augmented reality and autonomous robotics are few which are used in all sort of organizations both producing tangible and intangible products.

Organizations use IR 4.0 technologies to create capabilities to outperform their competitors, become agile, create sustainability, and improve operational performance, all in their excellent business interest. The awareness created by U.N. SDGs 17 goal is also making environment congenial to incline governments and companies to follow sustainability. Due to free social media and the internet, consumers are more aware of their rights, environment, and community, which could backfire for businesses to exploit natural resources, people, or the community. Schools and colleges are also educating the masses about sustainability while governments across the globe are aggressively working to achieve UN SGDs 17 goal before the year 2030 . C.E. practices are getting much attention from academicians, environmentalists, and businesses worldwide in sustainability. The company is interested in implementing C.E. practice as it helps to reduce the cost of virgin material, increases sustainability, captures market share, and thus results in an increase in revenue. The C.E. practices base on the idea of 3 R's "reuse, refurbish, and recycle." The practices start at the product development phase. The product is design with components that could reuse for producing the same product or in an entirely different product line or recycle to use as raw material. Thus, the practices in many ways increase the organization's financial strength.

Similarly, like C.E. practices, for organizations to increase O.P. also very important. The O.P. provides a status of how organizations are performing in the context of their core operations. The increased O.P. implies that the organization produces outputs within a specified cost, time, quality, quantity, and wastages while using minimum resources in the process. The decrease in O.P. leads the company to bear monetary losses and opportunities that the market could bring. Organizations remain vigilant and consistently trying to create capabilities that help to increase O.P. The significance of the three factors makes them valuable to the 
organization. For the same reason, the three factors combine inquest to understand their impact on organizational E.P. The insight would contribute to the literature and help academicians understand the phenomena for future research while providing policy implications for managers and decision-makers in business organizations.

\section{LITERATURE REVIEW OF USE}

\subsection{Industrial Revolution 4.0}

Research in IR 4.0 is gaining momentum. Services and manufacturing industries considering it a priority to implement according to their dynamics. The tools and digital technologies integrate functions and stakeholders to share information and knowledge all over the supply network [1]. Due to the extensive data sharing capability through the technology, many manufacturing organizations can now automate all critical and normal operating activities. Many real-time data sharing capabilities Intra and inter-organization also mitigate risk, provide higher visibility, and make the supply chain resilient. IR 4.0 uses digital sensors: "temperature, pressure, flow, weight, density, power utilization, demand, supply, and other logistic information" to create unstructured data. The data is shared via a wireless network and store in the cloud server to process in a central location to transform into information for decision making in all critical operations with the help of artificial intelligence. The live vast data collection from all directions of the supply chain enables the organization to contemplate forecast much better and correct according to supply and demand. Forecasting with lesser errors increases efficiency, better utilization of resources, and improved material flow in the supply chain.

Parallel to supply chain improvement, IR 4.0 also helps to increase innovative manufacturing capabilities with the help of IoT and A.I. The technology allows to diligently plan transport planning, material scheduling, production plan, and machine loading, and maintenance based on schedule deliveries. Due to IR 4.0, the system constantly produces a large volume of data as resources and assets are connected with the network. The data generated is transformed into complete meaningful information through data mining and data analytics that product developers, engineers, and functional managers plan for the future. The product developers and engineers are incorporating the technology to use C.E. practices. Technologies like 3D printing, digital technologies, and machine control are now used to implement C.E. practices to design processes and products to implement the 3R's to utilize scarce resources better to create sustainability. The other pronounced benefit discussed in literature from the IR 4.0 is operational efficiency, effectiveness, and flexibility to impact O.P. IR 4.0 is nascent and requires more dept understanding to use the technology diligently for desired results.

The C.E. practices use IR 4.0 to facilitate reusing, refurbishing, and recycling. The technology and C.E. practices are a complete paradigm shift for business organizations to innovate and increase economic performance. Concerning IR 4.0 and C.E. practices: blockchain now prevails that academic discussion due to technology pragmatism, reliability, transparency, and traceability in creating the required sustainability. The academician and practitioner are to reduce the ecological footprint by embedding sustainability into business operations which open the gate for a theoretical framework which is known as "ecological modernization theory (EMT)" [2]. The EMT states that a firm improves sustainability and E.P. by employing technological innovation to utilize resources efficiently.

\subsection{Industrial Revolution 4.0 and Circular Economy Practices}

Industry 4.0 and C.E. practices are most trending in academic research in the context of a firm's sustainability and operational productivity [3]. The IR 4.0, with the help of sensors throughout the system, gathers accurate real-time data with traceability to facilitate C.E. practices by answering its contemporary challenges. The current difficulties entail procurement of raw material, reuse, refurbish, recycling, and inculcating circular design to induce flexibility in production systems. Further, the challenges firms in the current era face are carbon footprint, which needs energy and resource preservation. The C.E. practices are constantly evolving because IR 4.0 is through its vast data process throughout the supply chain.

Researchers argue that IR 4.0 applications provide information to serve as stimuli to evolve C.E. practices. The report helps provide the required comparison to better the current systems placed in the firm. A better system reduces carbon footprint, systematic wastes and improves product life cycle for high-quality products. The velocity of innovation is helping researchers and designer to develop a circular model which best suits the business requirement and best fit according to organizational and industry dynamic. For the reason and benefits, IR 4.0 and C.E. practices are gaining importance in organizational research. Based on the above literature review and the advantages firm can exploit, below proposed the first hypothesis of the study at hand:

H1: Industry 4.0 increase the effectiveness of circular economy practices.

\subsection{Industrial Revolution 4.0 and Operational Performance}

According to [4], O.P. basis on reliability, operational and material cost, lead times, and inventory turnover cycle. The researcher argued that IR 4.0 could improve operational performance; however, the empirical research reflects weak support between the two factors [4]. Other researchers established that IR 4.0 increases productivity by reducing transportation time, lead time, and cost minimization. The operational capability having a positive relationship is in the 
context of lean manufacturing practices. Researchers found that IR 4.0 integration with O.P., especially in lean manufacturing practices, strongly impacts the E.P.

The organization's objective is to increase O.P., leading to a better E.P. [3]. The E.P. entails the overall cost of the processes starting from raw material procurement, manufacturing, energy consumption, forward and reverses logistics, and the 3R's. A similar study also examined and published results which reflects that IR 4.0 with support of O.P. (in lean practices context) impacts the firm triple bottom line and organizational performance. Based on the above literature review, we proposed below two hypotheses for the study:

H2: Industry 4.0 improves operational performance.

H3: Operational performance positively correlates with economic performance.

\subsection{Circular Economy Practices and Economic Performance}

The C.E. practices adopting manufacturing improve production efficiency, resource utilization, and energy conservation, leading to higher E.P. The C.E. practices adopted by the organization attribute implementation of circular design for a production system, circular procurement for buying of raw material, and the 3R's ("recycle, refurbish and reuse"). By implementing C.E. practices, firms realize economic benefits.

On the contrary, a firm with poor C.E. practices result in increased overhead cost, system inefficiencies, and reduce product innovation. Due to high consumer awareness on the topic, customers also prefer to buy products from companies that believe and reflect sustainability by their activity. Sustainability entails a low carbon footprint in all dimensions of the business.

The companies with induced sustainability and C.E. practices produce the product at a higher price. Customers are not price-sensitive for such products and are willing to buy even at higher rates than organizations with poor or no C.E. practices emplaced. Several other studies are available in the literature that advocate what C.E. practices increase or help to boost organizational E.P. and net profitability. The research draws the relation based on C.E. practice impact on the material cost used to manufacture the product. The direct material cost traced in the product ranges from $30 \%$ to $65 \%$. However, there is an exception, especially in a product with a patent cost involved, like the pharma industry. The outcomes for such industry might have less material cost; however, patent and research cost very high which increase prices at the end. Based on the above literature review, below is the proposed hypothesis for the study:

H4: Circular economy practices improve economic performance.

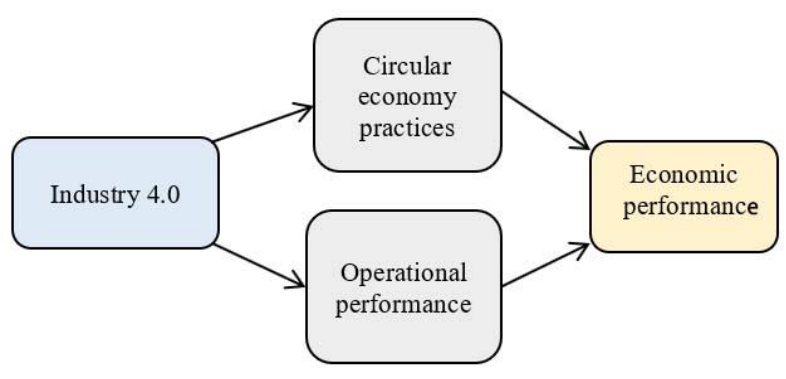

Figure 1. Research model

\section{PROBLEMS AND METHODOLOGY}

The study's objective is to analyze how IR 4.0 influences O.P. and C.P., which then impacts E.P. in sustainable development in Pakistan. For the study, a total of 540 manufacturing organizations were selected. The data was collected by survey strategy for the current cross-sectional study. Each questionnaire had items covering all three variables IR 4.0, C.E., O.P., and E.P. The respondent took 15 to 20 minutes to fill the questionnaire. The target respondents for the study were line managers, directors, and decision-makers available to fill the questionnaires. Google form was used to send a questionnaire to all respondents via email. The questionnaire was based on the Likert scale, where respondents can select any of the scores from 1 to 5 . Out of the selected 540 respondents, only 371 respondents replied with filled questionnaires. The filled forms were further reduced to 332 from as 39 forms were reported with missing data or not correctly filled. The total response rate for the study was $61.48 \%$. For the empirical research, the SEM was applied to test the data. The statistical testing begins with instrument reliability and validity. Once the result established the reliability and validity, the construct was tested for discriminant validity on $5 \%$ and $1 \%$. The proposed model was also tested for model fitness to ensure higher quality. Once the quality of the instrument, construct, and model was established, the data were calculated for parameters estimation to realize hypothesis analysis. The data collected during the pandemic was brought forward some limitations. However, Google Forms and online data collection mitigated the risk of no response. The link to the google form was emailed to all respondents. The researcher remains in contact with respondents to answer any queries during the process.

\section{RESULTS AND DISCUSSION}

\subsection{Instruments Reliability and Validity}

To assess empirical study reliability and validity are essential tools for assessment. The quality of the instrument is ensured by reliability as it confirms that on multiple-use, the outcomes will remain the same. For accuracy of the results, validity is inferred (see "Table 1" for results). 


\subsubsection{Factor loading}

To ensure that each construct substantially affects the studied variable factor, we review factor loading. The factor loading of all items ranges between 0.6 to 0.9 . The results are higher to the required limit of values $|0.4|$.

\subsubsection{Cronbach's Alfa}

Cronbach's Alfa tells us how close the items in the group are associated, which reflects internal consistency. The Cronbach's Alfa is above the minimum 0.7 for all items.

\subsubsection{Average Variance Expected}

The required minimum AVE is 0.5 , and "Table 1" displays all values to be above 0.5 and near 0.7 . The values can better explain latent variables.

\subsubsection{Composite Reliability}

To ensure internal reliability, C.R. is calculated for the items used. The acceptable threshold is a minimum of 0.5. "Table 1 " reflects C.R., which is 0.8 .

Table 1. Reliability and Validity

\begin{tabular}{|l|c|c|c|c|c|}
\hline Construct & Items & $\begin{array}{c}\text { Factor } \\
\text { Loading } \\
\text { Ranges }\end{array}$ & $\begin{array}{c}\text { Cronbach's } \\
\text { Alpha }\end{array}$ & AVE & CR \\
\hline CE & 12 & $0.735-0.887$ & 0.911 & 0.636 & 0.870 \\
\hline
\end{tabular}

\begin{tabular}{|l|l|l|l|l|l|} 
IR 4.0 & 6 & $0.777-0.914$ & 0.924 & 0.688 & 0.897 \\
\hline OP & 5 & $0.745-0.888$ & 0.901 & 0.662 & 0.851 \\
\hline EP & 4 & $0.679-0.892$ & 0.886 & 0.666 & 0.827 \\
\hline
\end{tabular}

\subsection{Discriminant Validity}

The correlation estimates are calculated to verify discriminant validity. The measure variance is used for the analysis. "Table 2" depicts higher AVE values than correlation results see "Table 2". The findings from the research suggest that construct differs among each other.

Table 2. Reliability and Validity

\begin{tabular}{|c|c|c|c|c|c|c|}
\hline Construct & F.P. & C.E. & O.P. & I4.0 & Mean & S.D. \\
\hline E.P. & - & & & & 3.48 & 0.597 \\
\hline $\mathrm{CE}$ & $0.521 * *$ & - & & & 2.96 & 0.491 \\
\hline OP & $0.472 *$ & $0.325^{*}$ & & & 3.31 & 0.561 \\
\hline I4.0 & 0.485 & $0.515 * *$ & $0.259^{*}$ & - & 4.52 & 0.748 \\
\hline
\end{tabular}

\subsection{Model Fitness}

The model fitness is assessed based on gamma and beta paths to measure the theoretical model. The chi-square value has an essential role for the study in hypothesis testing. The value of chi-square should be less than 3 . The current testing of the data suggests that the value is lower than and stands at 1.291 (see Table 3 in Appendix I). The other indicators in the table also reflect that the values extracted after the test suggest that the model fits testing.

Table 3. Table 3 Model Fitness

\begin{tabular}{|c|c|c|c|c|c|c|c|c|c|}
\hline Fit induces & NNFI & NFI & CFI & GFI & AGFI & TLI & $\chi^{2 / \mathrm{df}}$ & RMSEA & SRMR \\
\hline Criteria & $\geq 0.90$ & $\geq 0.90$ & $\geq 0.90$ & $\geq 0.90$ & $\geq 0.90$ & $\geq 0.90$ & $\leq 3$ & $\leq 0.08$ & $\leq 0.08$ \\
\hline Structural model & 0.922 & 0.923 & 0.925 & 0.911 & 0.922 & 0.931 & 1.291 & 0.039 & 0.026 \\
\hline
\end{tabular}

Table 4. Standardized parameter estimates

\subsection{Parameters Estimates}

The results for the parameter estimation are displayed in "Table 4". The reflected results suggest that the hypothesis is supported. $\mathrm{H} 1$ explains that at a significance level of $1 \%$. Increasing 1 of IR 4.0 would increase 0.515 of CEP. The results are consistent with an earlier study by [6] and [7]. H2 explains that at the significance level, 5\% increasing IR 4.0 by increase 1 and O.P. would increase 0.386. The O.P. increase E.P. significantly less compared to CEP (check H3). The results are consistent with to earlier study by [4]. $\mathrm{H} 3$ explains that at a significance level of $5 \%$, increasing 1 O.P. would increase E.P. by 0.721 . The results are consistent with an earlier study by [8] and. Finally, H4 explains that at a significance level of $1 \%$ increasing CEP by 1 would increase E.P. 1. The results are consistent with an earlier study by [3] and [10].

\begin{tabular}{|c|l|c|c|c|}
\hline Hypothesis & \multicolumn{1}{|c|}{ Paths } & $\begin{array}{c}\text { Standardized } \\
\text { estimate }\end{array}$ & $\begin{array}{c}\text { p- } \\
\text { value }\end{array}$ & Results \\
\hline H1 & I4.0 $\rightarrow$ CEP & $0.515^{* *}$ & 0.001 & Supported \\
\hline H2 & I4.0 $\rightarrow$ OP & $0.386^{*}$ & 0.045 & Supported \\
\hline H3 & OP $\rightarrow$ EP & $0.721^{*}$ & 0.025 & Supported \\
\hline H4 & CEP $\rightarrow$ EP & $0.634^{* *}$ & 0.000 & Supported \\
\hline
\end{tabular}

${ }^{\text {a. }}$ Note: $* *$ and $*$ shows the significance level at $1 \%$ and $5 \%$, respectively.

\section{CONCLUSION}

In the new era of consumerism, where sustainability is much in demand, organizations constantly try to improve production systems to produce products and services by reducing carbon and ecological footprint. IR 4.0 is a technology that enhances sustainability by increasing the impact of C.E. practices on firm performance, significantly 
impacting net profits. The advantage of IR 4.0 is dual as it supports O.P. in a firm. The O.P. improves the ability to move and transform material in a product. The IT 4.0 improves the transformation process at a faster rate with higher accuracy. The improvement of O.P. also translates to better firm E.P. The research conducts in Pakistan, making the study valid to generalize for a developing country. The results provide insights into the unique nexus of IR 4.0, C.E. practices, O.P. and E.P. The research results highlight the importance of IR 4.0 as it could provide multiple advantages if implemented correctly.

The study provides direction for future studies; the research offers a relevant model that more added factors could further study regressors to understand the relationship between IR 4.0, C.E. practices, O.P., and E.P. Besides academicians, the research also provides managers with policy implications stated as below:

- Business and educational institutes should collaborate to promote sustainability. The strategy will enable a congenial environment for better think as a collective approach from the society.

- Manufacturing enterprises and HEIs should collaborate to open training centers and promote research culture to develop new ideas to use circular economy practices. Academia can be the most significant contributor in the cause to help businesses identify critical success factors for implementing C.E. practices and technology to increase it.

- I.T. infrastructure needs to revamp to an extent to implement IR 4.0 technology in companies. The organization should not discard the old system but utilize it better-companies sometimes, in redesigning the process, waste many valuable resources.

- Companies should identify resources that could connect to IR 4.0 with some modifications. This will save much capital in investing in new technology.

- For a developing country, the human interface could also connect between machine and IR 4.0 network. However, delays and errors in information collected should also be compensated. Engineers and supply chain personal should evaluate the human interface for data errors for better compensation. This will require training of the human resource.

- CEOs and directors should provide funds for training and infrastructure and encourage employees for the transformation.

- Companies should engage with employees to promote the idea of new technology as new technologies and their benefit. Usually, automation in a developing country is looked at with suspicion as it reduces labor demand in manufacturing.
- The system transformation from convention technology to IR4.0 should be gradual and subtle. Companies to create sustainability and adopt technologies which do not hurt labor job. The developing countries need to be careful in this regard.

\section{ACKNOWLEDGMENT}

This research is supported by the Beijing Key Laboratory of Urban Spatial Information Engineering (NO. 20210218) and China's National Natural Science Foundation (No. 202202457).

\section{REFERENCES}

[1] Dev, N. K., Shankar, R., \& Swami, S. (2020). Diffusion of green products in industry 4.0: Reverse logistics issues during design of inventory and production planning system. International Journal of Production Economics, 223, 107519.

[2] Murphy, J., \& Gouldson, A. (2000). Environmental policy and industrial innovation: integrating environment and economy through ecological modernisation. Geoforum, 31(1), 33-44.

[3] Khan, S. A. R., Razzaq, A., Yu, Z., \& Miller, S. (2021). Industry 4.0 and circular economy practices: A new era business strategies for environmental sustainability. Business Strategy and the Environment, n/a(n/a). https://doi.org/https://doi.org/10.1002/bse.2853

[4] Lee, K. S., Nor, N. M., \& Ismail, F. (2021). Industry 4.0 and Lean Manufacturing Practices: An Approach to Enhance Operational Performance in Singapore's Manufacturing Sector. Research in Management of Technology and Business, 2(1), 456-472.

[5] de Sousa Jabbour, A. B. L., Jabbour, C. J. C., Godinho Filho, M., \& Roubaud, D. (2018). Industry 4.0 and the circular economy: a proposed research agenda and original roadmap for sustainable operations. Annals of Operations Research, 270(1), 273-286.

[6] Nascimento, D. L. M., Alencastro, V., Quelhas, O. L. G., Caiado, R. G. G., Garza-Reyes, J. A., RochaLona, L., \& Tortorella, G. (2019). Exploring Industry 4.0 technologies to enable circular economy practices in a manufacturing context. Journal of Manufacturing Technology Management, 30(3), 607-627. https://doi.org/10.1108/JMTM-03-2018-0071 
[7] Bai, C., Dallasega, P., Orzes, G., \& Sarkis, J. (2020). Industry 4.0 technologies assessment: A sustainability perspective. International Journal of Production Economics, 229, 107776.

[8] Feng, M., Yu, W., Wang, X., Wong, C. Y., Xu, M., $\&$ Xiao, Z. (2018). Green supply chain management and financial performance: The mediating roles of operational and environmental performance. Business Strategy and the Environment, 27(7), 811-824. https://doi.org/https://doi.org/10.1002/bse.2033
[9] Lee, J. (2019). Effects of operational performance on financial performance. Management Science Letters, 9(1), 25-32.

[10] Rehman Khan, S. A., Yu, Z., Sarwat, S., Godil, D. I., Amin, S., \& Shujaat, S. (2021). The role of blockchain technology in circular economy practices to improve organisational performance. International Journal of Logistics Research and Applications, 1-18. https://doi.org/10.1080/13675567.2021.1872512 